\title{
Molecular modeling of fibronectin adsorption on topographically nanostructured rutile (110) surfaces
}

\author{
Chuangqiang Guo, ${ }^{\mathrm{a}, 1}$ Chunya Wu, ${ }^{* a, 1}$ Mingjun Chen, ${ }^{\mathrm{b}, 1}$ Ting Zheng, ${ }^{\mathrm{b}}$ Ni Chen, ${ }^{\mathrm{b}}$ Peter T. \\ Cummings ${ }^{\mathrm{c}}$
}

${ }^{a}$ State Key Laboratory of Robotics and System, Harbin Institute of Technology, Harbin, Heilongjiang 150080, China

${ }^{b}$ School of Mechatronics Engineering, Harbin Institute of Technology, Harbin, Heilongjiang 150001, China

${ }^{c}$ Department of Chemical \& Biomolecular Engineering, Vanderbilt University, Nashville, Tennessee 37235-1604, United States

${ }^{1}$ These authors contributed equally to this work.

* Corresponding author.

E-mail addresses: chunya.wu@hit.edu.cn

telephone: +86-451-86403252; fax: +86-451-86403252

Postal address: Room 508, Zhizao Building, Harbin Institute of Technology, No.92 West

Dazhi Street, Nangang District, Harbin, Heilongjiang 150001, China.

Co-authors

Chuangqiang Guo: guochuangqiang@126.com

Mingjun Chen: chenmj@163.com

Ting Zheng:whlgzt@163.com

Ni Chen: chenni900414@163.com

Peter T. Cummings: peter.cummings@ @anderbilt.edu 
Abstract. To investigate the topographical dependency of protein adsorption, molecular dynamics simulations were employed to describe the adsorption behavior of the tenth type-III module of fibronectin $\left(\mathrm{FN}-\mathrm{III}_{10}\right)$ on nanostructured rutile (110) surfaces. The results indicated that the residence time of adsorbed $\mathrm{FN}-\mathrm{III}_{10}$ largely relied on its binding mode (direct or indirect) with the substrate and the region for protein migration on the periphery (protrusion) or in the interior (cavity or groove ) of nanostructures. In the direct binding mode, $\mathrm{FN}-\mathrm{III}_{10}$ molecules were found to be 'trapped' at the anchoring sites of rutile surface, or even penetrate deep into the interior of nanostructures, regardless of the presented geometrical features. In the indirect binding mode, $\mathrm{FN}-\mathrm{III}_{10}$ molecules were indirectly connected to the substrate via a hydrogen-bond network (linking $\mathrm{FN}-\mathrm{III}_{10}$ and interfacial hydrations). The facets created by nanostructures, which exerted restraints on protein migration, were suggested to play an important role in the stability of indirect $\mathrm{FN}-\mathrm{III}_{10}-$ rutile binding. However, a doubly unfavorable situation - indirect $\mathrm{FN}-\mathrm{III}_{10}$-rutile connections bridged by a handful of mediating waters and few constraints on movement of protein provided by nanostructures-would result in an early desorption of protein.

Keywords: Nanostructure; protein adsorption; rutile; molecular dynamics simulation 


\section{Introduction}

Adsorption of proteins at a solid-liquid interface is an important phenomenon in biology and highly relevant for the design of implant with excellent biocompatibility. ${ }^{1,2}$ When a biomaterial comes into contact with a biological milieu containing cells, the soluble proteins adsorb onto the surface of biomaterial rapidly, saturating it within a time frame of seconds to minutes. ${ }^{3}$ Therefore, living cells may never see the native biomaterial, and the cell-surface interplay is ultimately an interaction between cells and surface-bound protein layer. ${ }^{4}$ That is, the cellular response to the biomaterials largely depends on the speciation, conformation and orientation of the bound protein layers, whereas the geometrical properties of surfaces can be conveyed indirectly through the adsorbed proteins. ${ }^{5}$ Hence, the local changes, especially in the nanoscale surface topographies, may lead to changes in quantity, density and orientation of the adsorbed proteins; thus attention needs to be paid to understand how the protein perceives its substrate.

Many experimental approaches have been applied to figure out whether the existence of nano-scale geometrical characteristics of substrates can enhance protein adsorption, or which kind of nanostructure may act as a preferred site for protein deposition. De Luca et al. ${ }^{6}$ found that fibronectin was adsorbed onto the microgrooved metallic surfaces at low concentrations, and the protein molecules were observed to selectively aggregate at the groove/ridge boundaries. Huang et al. ${ }^{7}$ prepared the $\mathrm{TiO}_{2} /$ silicate hierarchical coatings with various nanostructures on titanium substrates, finding that the improvement of fibronectin adsorption was morphological dependent according to the trend: nanoleaf coating >nanoplate coating >nanorod coating. Giamblanco et al. ${ }^{8}$ fabricated chemically homogeneous nanostructured surfaces of variable local curvature, concluding that the local curvature was strongly correlated with the kinetic adsorption phase and rate of laminin adsorption on the nanostructured surfaces. The dependence of protein adsorption on nano-scale patterned surface was also confirmed in the AFM-based force spectroscopy experiments ${ }^{9}$ and the radiolabeling experiments. ${ }^{10}$ The fibronection tended to adsorb preferentially in the concave grooves on the surface of boron-doped silicon wafers. ${ }^{9}$ Similarly, the adsorbed fibrinogen was shown to be regularly distributed most on the flanks and valleys of the dot-like protrusions, but sprinkled throughout the flat surface of poly(dimethylsiloxane). ${ }^{10}$ 
The current researches suggest that proteins are sensitive to the nanoscale environment of anchoring surface, probably even showing special affinity for certain type of nanostructures. That is, although the protein-surface systems cover a huge diversity, a detailed understanding of how the individual proteins attach to artificially nanostructured surfaces on a molecular level is urgently required. Compared to the experimental approaches, computational methods, which could eliminate occasional influences of experiments and create plausible structural models of proteins on solid surfaces, seems to be a feasible option to reveal the interaction mechanism between the surface of biomaterials and proteins. Monti ${ }^{11}$ and Walsh ${ }^{12}$ conducted molecular dynamics (MD) simulations to understand the adsorption of polypeptides on the strongly polar surfaces with explicit water, observing that binding is not to the surface itself, but rather to a structured water layer on the surface. Yang et al. ${ }^{13}$ believed that the driving force for protein binding on the titania nanotubes derived from the physical adsorption on the basis of MD simulations. Raffaini and Ganazzoli ${ }^{14}$ adopted MD simulations to assess the effect of surface curvature of single-walled carbon nanotubes (SWNT) on protein adsorption, finding that the adsorption strength was slightly weaker on the outer convex surfaces of SWNT and was conversely enhanced on the inner concave surface of SWNT. Our group performed MD simulations to figure out the influence of cation mediation in peptide-surface interaction, observing that the divalent cations seemed more effective than the monovalent cations in bridging the negatively charged adsorbate to the negatively charged adsorbent, ${ }^{15-17}$ as reported in some experimental studies. ${ }^{18,19}$

MD simulations were also adopted in the present work to describe early adsorption of a fragment of fibronectin $(\mathrm{FN})$ onto the nanostructured surfaces. FN is a major component of the extra-cellular matrix in tissue, which influences cell adhesion and migration through interactions with other extra-cellular components as well as with cell surface receptors. ${ }^{20} \mathrm{FN}$ comprises three different kinds of homology units referred to as types I-III, and the $10^{\text {th }}$ Type III module $\left(\mathrm{FN}-\mathrm{III}_{10}\right)$ contains the important cell-binding sequence-arginine-glycine-aspartic acid (Arg-Gly-Asp, RGD). ${ }^{21}$ The RGD sequence serves as a primary cell attachment cue and modulates the cell adhesion by being linked to integrin receptors located at the cell membrane, i.e., $\alpha_{5} \beta_{1}, \alpha_{x} \beta_{1}$ and $\alpha_{3} \beta_{1}{ }^{21}$ Therefore, FN-III 10 was selected as the adsorbate and the most stable phase of $\mathrm{TiO}_{2}$ polymorphs at ambient temperature-rutile ${ }^{22}$ was chosen to be the adsorbent. As 
is well known, the hydroxyl coverage of a native oxide film formed on a Ti-surface depends on the adsorption state of water; however, whether water dissociates upon adsorption on the $\mathrm{TiO}_{2}$ surface remains controversial. The common view based on experiments ${ }^{23-25}$ is that water adsorbs molecularly on the ideal $\mathrm{TiO}_{2}(110)$ surface and dissociation prefers to take place at defect sites, however, several recent experimental studies have presented evidences for the presence of a dissociated species on the defect-free surfaces. ${ }^{26,27}$ In theoretical studies, a delicate balance between dissociated, partial dissociated, and molecular adsorption of water is suggested. ${ }^{28-30}$ In light of this, it is hard to gain a clear-cut answer to whether water adsorbs associatively or there is dissociation of water to produce hydroxyl sites on the $\mathrm{TiO}_{2}$ surface on the basis of the available information. Moreover, the focus of this work is to assess the influence of geometrical features of substrate on the adsorption behavior of protein, thus three nonhydroxylated rutile (110) surfaces characterized with different types of nanostructures (i.e., protrusion, cavity or groove) were introduced here. Meanwhile, the evaluation and structural optimization of hydrated/hydroxylated step edges of rutile (110) surface, which could be applied to the protein/rutile/aqueous solution system, will be covered in another paper of ours. ${ }^{31}$

\section{Simulation methods}

The MD simulations of FN-III 10 -rutile assembly in aqueous solution were carried out in the NVT ensemble, where the number of particles $(\mathrm{N})$ and volume $(\mathrm{V})$ of the system are held constant and the temperature $(\mathrm{T})$ is in equilibrium with that of its heat bath. The rutile (110) surface was reproduced through the Matsui and Akaogi parametrization. ${ }^{32}$ Since a single $\mathrm{FN} \mathrm{III}_{10}$ molecule can be enveloped in an ellipsoid with an approximate dimension $43 \AA \times 19$ $\AA \times 17 \AA,{ }^{33}$ the nanostructures in this work were built with dimensions in the same order as the protein segment, in order to get a detailed understanding of the influence of surface nanotopographies on protein adsorption. The dimensional details of protrusion, cavity and groove are shown in Figure 1. The Amber force field ${ }^{34}$ was utilized to describe the protein and the SPC/E water model ${ }^{35}$ was chosen to represent the solvent. The interaction potentials between amino acid residues/water and rutile atoms were obtained from the literature, ${ }^{36}$ and the parameters of Lennard-Jones potential for the cross interactions between nonbonded atoms followed the Lorentz-Berthelot rule. ${ }^{37}$ The simulation box with the size roughly equal to 
$142 \times 130 \times 80 \AA^{3}$ was filled with water molecules, the density of which was set to the value corresponding to $1 \mathrm{~atm}$ of solution pressure. Periodic boundary conditions were applied in the $x-$ and $y$-direction, and a reflecting boundary condition was applied in the $z$-direction. The Nosé-Hoover thermostat ${ }^{38}$ was used to control the temperature and the particle-particle particle-mesh (PPPM) solver ${ }^{39}$ was employed to handle the long-rang electrostatic interactions.

The FN-III 10 molecules were put close to the nanostructured rutile surfaces with different arrangement, maintaining the initial distances from any atom of $\mathrm{FN}-\mathrm{III}_{10}$ to the rutile atoms larger than $4.5 \AA$. The solute (FN- III $_{10}$ and rutile) was kept frozen first to randomize the position of water molecules, but the constraints were removed after an energy minimization (corresponding to approximate $0 \mathrm{~K}$ ), only keeping the lowest layer of rutile fixed till the end of simulations. The system temperature was then increased gradually from $0 \mathrm{~K}$ to $300 \mathrm{~K}$ in increments of $50 \mathrm{~K}$ every $250 \mathrm{ps,}$, with the $\mathrm{FN}-\mathrm{III}_{10}$ treated as an independent rigid body, which moved and rotated as a single entity (i.e., body movement). After that, the systems were relaxed at $\mathrm{T}=310 \mathrm{~K}$ for $1 \mathrm{~ns}$ with position restraints on the backbone atoms of amino acid residues (i.e., restraining movement), and the resulting configurations were equilibrated without any constraint for $8 \sim 16 \mathrm{~ns}$, depending on the specific state of different molecular assemblies.

\section{Results}

In the MD simulations, $\mathrm{FN}-\mathrm{III}_{10}$ molecules were initially put close to the rutile surface without any direct connection. The proteins remained in the immediate vicinity of nanostrucures after the 'body' and 'restraining' movements were the focus of this work, and seven typical configurations shown in Figure 2 were selected to proceed to the production run. Proteins can 'sense' the topography of surfaces at the nanometer scale; ${ }^{40-43}$ but the research to gain a detailed understanding of how different surface nanostructures affect the binding affinity of proteins is still in its infancy. Therefore, the emphasis here was to test whether the protein can keep within the region of nanostrucures, or even break through the screen of interfacial hydrations, forming direct interactions with the rutile surface.

\subsection{Adsorption behavior of FN-III I0 $_{10}$ molecule on protrusions}

Three FN-III ${ }_{10}$-protrusion assemblies were introduced, with the protein segments located above the planar region, at the juncture of flank and planar region, and on the top of summit, 
respectively. For clarity, these $\mathrm{FN}-\mathrm{III}_{10}$ molecules were called 'FN-III $10-\mathrm{P} 1$ ', 'FN-III $10-\mathrm{P} 2$ ', and ' $\mathrm{FN}-\mathrm{III}_{10}-\mathrm{P} 3$ ' in sequence. The evolution of minimum distances from $\mathrm{FN}-\mathrm{III}_{10}$ to different parts of surface are shown in Figure 3. FN- $\mathrm{III}_{10}-\mathrm{P} 1$ remained in the vicinity of both flank and planar region rather early, moving toward the bulk solvent after $\mathrm{t}=4 \mathrm{~ns}$. FN- $\mathrm{III}_{10}-\mathrm{P} 2$ stayed within the planar region for another $1.5 \mathrm{~ns}$ after its departure from the flank of protrusion. The minimum distances from $\mathrm{FN}-\mathrm{III}_{10}-\mathrm{P} 3$ to the summit and flank fluctuate widely during the early stage of equilibration period, but reach a plateau after $\mathrm{t}=5 \mathrm{~ns}$. The minimum $\mathrm{FN}-\mathrm{III}_{10}-\mathrm{summit}$ distance of $\sim 2.0 \AA$ indicates that direct connections between $\mathrm{FN}-\mathrm{III}_{10}-\mathrm{P} 3$ and the summit of protrusion should have been formed during the final $3 \mathrm{~ns}$ of MD simulation.

The typical spatial arrangements of $\mathrm{FN}-\mathrm{III}_{10}$ on the rutile surface with a single protrusion are shown in Figure S1 Figure S3 in the supporting information. FN-III $10-\mathrm{P} 1$ presented a 'standing up' configuration, keeping the C-terminal carboxyl group hydrogen-bonded to the first- and second-layer water molecules (Figure S1 in the supporting information). However, the indirect $\mathrm{FN} \mathrm{III}_{10}-$ rutile connections mediated by very few water molecules were too weak to 'trap' the protein on the surface. On the contrary, $\mathrm{FN}-\mathrm{III}_{10}-\mathrm{P} 2$ exhibited a 'lying down' configuration (Figure S2 in the supporting information), possessing a relatively larger contact area with the planar region; thus the protein could remain there for a longer time after its departure from the flank. The FN-III $10-\mathrm{P} 3$ finally settled down on the protrusion, forming direct hydrogen bonds with the doubly coordinated bridging $\mathrm{O}$ atoms $\left(\mathrm{O}_{\mathrm{BO}}\right)$ via the guanidine group in residue Arg93 (Figure S3 in the supporting information). The guanidine group would occasionally hop along the [001] direction, but the $\mathrm{H}_{\mathrm{NH}_{2}}-\mathrm{O}_{\mathrm{BO}}$ distance basically met the criterion of hydrogen-bond length during the final 3 ns of equilibration stage.

\subsection{Adsorption behavior of FN-III 10 molecule on cavities}

For the rutile surface with a single cavity, the ' $\mathrm{FN}-\mathrm{III}_{10}-\mathrm{C} 1$ ' located at the juncture of inwall and planar region, and the ' $\mathrm{FN}-\mathrm{III}_{10}-\mathrm{C} 2$ ' settled inside the cavity were introduced, respectively. The minimum distance from $\mathrm{FN}-\mathrm{III}_{10}-\mathrm{C} 1$ to the valley of cavity (Figure 4) indicates that the protein remained more than $9 \AA$ away from the valley within the first $3.7 \mathrm{~ns}$, but the former continued to approach the latter till the minimum distance between them plateaued out after $t=6.5 \mathrm{~ns}$. The snapshots in Figure 4 show that $\mathrm{FN}-\mathrm{III}_{10}-\mathrm{C} 1$ began to bind with the left inwall rather early. The 
entire protein flipped over around the anchoring site, finally reaching the valley to form hydrogen bonds with the interfacial water; thus, the anchoring site is of vital importance in determining the subsequent motion of adsorbate. To preferentially monitor the dynamic events occurring at the anchoring site, Figure 5 displays the evolution of distances from the carbonyl and amide groups in the side chain of residue Asn42 to the top-layer atoms of cavity inwall. It can be seen that a water molecule, directly bound to a 4 -coordinated $\mathrm{Ti}$ atom of inwall $\left(\mathrm{Ti}_{1}\right)$ at the very beginning of the production run, intermediated between the carbonyl oxygen $\left(\mathrm{O}_{\mathrm{CO}}\right)$ and the $\mathrm{Ti}_{1}$ atom (left inset), whereas the amide group located far away from the oxygens of inwall $\left(\mathrm{O}_{1}\right.$ and $\left.\mathrm{O}_{2}\right)$. At $\mathrm{t}=0.12 \mathrm{~ns}$, the water molecule adsorbed on $\mathrm{Ti}_{1}$ atom reoriented to make room for the $\mathrm{Ti}_{1}-\mathrm{O}_{\mathrm{CO}}$ bond, which subsequently acted as a fulcrum for the other parts of protein. The amide group of ASN42 swung mildly around the $\mathrm{Ti}_{1}-\mathrm{O}_{\mathrm{CO}}$ bond until the distance from it to $\mathrm{O}_{1}$ or $\mathrm{O}_{2}$ atom was close enough to form hydrogen-bonded connections (right inset).

FN- $\mathrm{III}_{10}-\mathrm{C} 2$ was located within the cavity in the primary stage of production run, but Figure 6a shows that the FN-valley minimum distance remained generally larger than $5 \AA$, whereas the FN-inwall minimum distance fell sharply to $2.3 \AA$ at $\mathrm{t}=5.0 \mathrm{~ns}$. Therefore, it can be inferred that although the protein was not able to form direct interactions with the top-layer surface atoms or the first-hydration shell on the valley, it may be directly bonded or hydrogen-bonded to the surface atoms on the inwall. Figure $6 \mathrm{~b}$ shows the radial distribution function (RDF) calculated for the specific protein atoms and the top-layer $\mathrm{TiO}_{2}$ atoms of inwall (Unless otherwise stated, the RDF data were averaged from the final 2 ns results of production run). The $\mathrm{O}_{\mathrm{si}}-\mathrm{N}_{\mathrm{NH}_{3}}+\mathrm{RDF}$ exhibits a first sharp peak centering at $\sim 2.95 \AA$, while the magnitude of $\mathrm{Ti}_{\mathrm{si}}-\mathrm{O}_{\mathrm{COO}}-\mathrm{RDF}$ begins to increase when $r$ exceeds $4.0 \AA$. That is, at least one $\mathrm{NH}_{3}{ }^{+}$group was within the immediate proximity to the $\mathrm{O}_{\mathrm{si}}$, allowing the formation of $\mathrm{N}_{\mathrm{NH}_{3}}+\ldots \mathrm{O}_{\mathrm{si}}$ hydrogen bonds. However, the carboxyl groups could not form direct bonds with the $\mathrm{Ti}_{\mathrm{si}}$ atoms, but a minority of them may form hydrogen bonds with the first-hydration shell. The typical conformation of $\mathrm{FN}-\mathrm{III}_{10}-\mathrm{C} 2$, shown in Figure $\mathrm{S} 4$ in the supporting information, confirms that the $\mathrm{NH}_{3}{ }^{+}$group in residue Arg6 did break through the water barriers, forming hydrogen bonds with $\mathrm{O}_{\mathrm{si}}$ on the inwall. There were five carboxyl groups (the involved residues include Glu9, Asp23, Glu38, Glu95 and Ile96) remaining in the interior of cavity, thus Figure S5 in the supporting information provides the RDFs between them and the water layers on the inwalls. The $\mathrm{COO}^{-}{ }_{1}$ basically kept 
hydrogen-bonded to the first-hydration shells of inwall I and II (refer to the illustration in Figure S5 in the supporting information), and the RDF magnitudes indicate that the persistence of hydrogen bonds between first-layer $\mathrm{O}_{\mathrm{w}}$ and $\mathrm{COO}_{1}^{-}$group is decidedly superior to those between first-layer $\mathrm{O}_{w}$ and the other four $\mathrm{COO}^{-}$groups. Meanwhile, the sharp peak of RDF between second-layer $\mathrm{O}_{\mathrm{w}}$ on the valley and $\mathrm{O}_{\mathrm{COO}^{-}}$suggests that $\mathrm{COO}_{4}^{-}$was stably bridged to the valley of cavity via the second-layer waters. Evidently, the carboxyl groups in the interior of cavity interacted actively with the surface hydration shells, thereby forming an intensive hydrogen-bond network.

\subsection{Adsorption behavior of FN-III 10 molecule on grooves}

The grooves run through in the $x$-direction with the width larger than that of cavities, resulting in a more extensive territory for protein activity. It can be supposed that the probability of $\mathrm{FN}-\mathrm{III}_{10}$ molecules arrive in the valley of groove is greater than the case in the cavity, since the proteins surrounded by four inwalls of cavity could readily interact with the constraint facets,

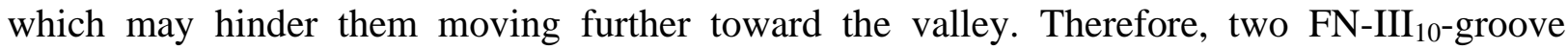
assemblies were selected, including one adsorbate located at the juncture of the inwall and planar region, and the other stayed on the top of groove valley. For clarity, the two $\mathrm{FN}-\mathrm{III}_{10}$ molecules were called ' $\mathrm{FN}-\mathrm{III}_{10}-\mathrm{G} 1$ ' and ' $\mathrm{FN}-\mathrm{III}_{10}-\mathrm{G} 2$ ', respectively.

The minimum distances from $\mathrm{FN}-\mathrm{III}_{10}-\mathrm{G} 1$ to the different parts of grooved surface, and the typical conformations are shown in Figure 7. The protein was originally far away from the valley, lying at the juncture of the inwall and planar region. The $\mathrm{NH}_{3}{ }^{+}$in the side chain of residue Lys86 was the only group interacting with the substrate, via the mediation of the firstand second-hydration shells on the left inwall of the groove. FN- $\mathrm{III}_{10}-\mathrm{G} 1$ gradually detached from the rutile surface after $3 \mathrm{~ns}$, but returned at $\mathrm{t}=\sim 11 \mathrm{~ns}$ with the height of protein varying slightly during the later stage. However, the link between the entire protein and the grooved surface was extremely weak, only depending on a few mediated water molecules.

FN-III $10^{-}-\mathrm{G} 2$ was contained in the interior of groove; thus Figure S6 in the supporting information only gives the minimum distances from the protein to the inwall and valley of groove, which fluctuate wildly during the first half of production run, then plateau. Since FN-III ${ }_{10}-\mathrm{G} 2$ could approach the groove with the minimum distance less than $3 \AA$, RDFs 
between specific protein groups and surface atoms/hydration shells were calculated to determine

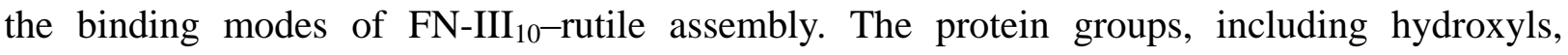
carbonyls, guanidines and amides, stayed too far away from the surface to induce any short-range interaction; thus only RDF information about carboxyl and amino groups is reported in Figure $\mathrm{S} 7$ in the supporting information. The $\mathrm{Ti}_{\mathrm{sv}}-\mathrm{O}_{\mathrm{COO}}-\mathrm{RDF}$ shows a first sharp

peak centering at $\sim 4.5 \AA$; however no distinct peak appears in the RDF curves of $\mathrm{Ti}_{\mathrm{si}}-\mathrm{O}_{\mathrm{COO}^{-}}$or $\mathrm{O}_{\mathrm{si}}-\mathrm{N}_{\mathrm{NH}_{3}}{ }^{+}$pair. There are two possible explanations for the above phenomena. One is that the overall $\mathrm{Ti}_{\mathrm{si}}-\mathrm{O}_{\mathrm{COO}^{-}}$and $\mathrm{O}_{\mathrm{si}}-\mathrm{N}_{\mathrm{NH}_{3}}{ }^{+}$distances vary randomly; thus the RDF curves resulting from statistical average would be a lot flatter. The other possibility is that the distances of a minority of individual $\mathrm{Ti}_{\mathrm{si}}-\mathrm{O}_{\mathrm{COO}}$ and $\mathrm{O}_{\mathrm{si}}-\mathrm{N}_{\mathrm{NH}_{3}}+$ pairs may fluctuate slightly, but the distribution features fade away after averaging out among all the available atom pairs.

For reasons given above, four carboxyls in the interior of groove and all the amino groups of FN-III 10 were selected to calculate the RDF data between them and the first-hydration shells (Figure 8). Referred from the positions of RDF first-peak centers, $\mathrm{COO}_{3}^{-}$should be the only functional group forming hydrogen bonds with the first hydration on the valley, whereas $\mathrm{COO}_{1}^{-}$, $\mathrm{COO}_{2}^{-}$and $\mathrm{COO}_{3}^{-}$could be hydrogen bonded to the first hydration on the inwall without exception. However, the magnitudes of first peaks indicate that the persistence of hydrogen bonds is in the following order: $\mathrm{COO}_{3}^{-} \ldots \mathrm{O}_{\mathrm{w}}>\mathrm{COO}_{2}^{-} \ldots \mathrm{O}_{\mathrm{w}}>\mathrm{COO}_{1}^{-} \ldots \mathrm{O}_{\mathrm{w}}\left(\mathrm{O}_{\mathrm{w}}\right.$ refers to oxygens of the first-hydration waters). Moreover, amino groups could occasionally get within close proximity to the first-hydration shell on the inwall, but stable hydrogen bonds were never formed. To visualize the FN-III 10 -rutile interaction, Figure 9 gives the typical conformations of

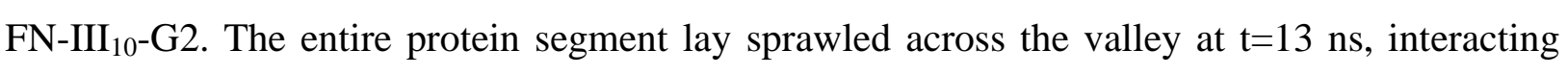
with both inwalls at the same time. Plenty of water molecules in the surface hydration shells were involved in the hydrogen-bond network with FN-III $10-\mathrm{G} 2$. However, the protein stayed farther away from the right inwall at $\mathrm{t}=15 \mathrm{~ns}$, leaving only the $\mathrm{COO}_{3}^{-}$group connected to the left inwall and valley of groove indirectly via the mediation of first- and second-layer water molecules, which agrees well with the order of persistence of $\mathrm{COO}^{-} \ldots \mathrm{O}_{\mathrm{w}}$ hydrogen bonds.

\section{Discussions}

FN is a very large protein $(480 \mathrm{kDa})$, which is difficult to be modelled in its entirety due to the 
computational capabilities; thus the researchers turned to model the typical segments of FN, which contain the putative binding sites for $\alpha_{5} \beta_{1}$ integrin-RGD sequence. ${ }^{45,46}$ Wilson et al. ${ }^{45}$ developed a new force field with implicit solvation to study the adsorption of the 7-10 type III repeats of FN on the alkanethiol self-assembled monolayers (SAMs) with four different terminal functionalities. Although the results from both Wilson's work and our work can provide some insight into the initial events of protein adsorption and subsequent trends for surface-induced changes in adsorbed conformation of the selected protein segments, they emphasized particularly on the influences from surface chemistry on the adsorption behavior of protein, whereas we are more interested in the influences from surface topography, especially the detailed shape of nanofeatures. Based on the present results, we find that the adsorption stability of protein relies on the geometrical features of nanostructures to a great extent. The protein segment in close proximity to protrusion generally interacts with up to one flank. Combined with the summit or planar region, there are two facets from the substrate capable of imposing position constraints on the protein at the utmost. The groove runs through in the $x$-direction and hence a total of three constraint facets, i.e., two inwalls plus valley, will contribute to the limited migration of protein. By contrast, the number of facets imposing restraints on the adsorbed protein reaches five for the cavity, including four inwalls and one valley. Therefore, the territory size for protein migration on the periphery (e.g., protrusion) or in the interior (e.g., cavity or groove) of nanostructures can be ordered as follows: protrusion>groove>cavity, which may explain the experimental results gained by Elter et al. ${ }^{9}$ that concave grooves seemed more favorable for fibronectin adsorption than convex summits. The convex summits in Elter's experiments resemble the presented protrusion in overall shape, and their concave grooves are similar to the state of the created grooves here. Elter et al. ${ }^{47}$ also conducted Brownian dynamics simulations to understand how lysozyme interacted with defined topographic nanostructures. An increased number of proteins were found in the concave corners of the grooves, and the sites near the flanks of the grooves stabilized the protein adsorption. These phenomena were attributed to the increased interactions with the substrate and restricted degrees of freedom during diffusion, which accords well with our point shown below that the territory size for protein migration, which depends on the detailed shape of nanostructures, plays an important role in affecting the stability of $\mathrm{FN}-\mathrm{III}_{10}$ adsorption. However, the proteins in Elter's work were 
described as uniformly rigid charged spheres and allowed to diffuse across the surface, so it was allowed to look at many proteins aggregating at a single groove flank; whereas what we are looking at is one single protein, which is already close to the substrate, with all the atomistic details considered. That is, we prefer to use all-atom molecular dynamics simulations to highlight the molecular level interactions at the $\mathrm{FN}_{-} \mathrm{III}_{10}-$-rutile interface in aqueous solution, by addressing how one single protein reaches or stays in the close proximity of the nanosturcture.

FN-III $10-\mathrm{P} 1$ with a 'standing up' configuration and $\mathrm{FN}-\mathrm{III}_{10}-\mathrm{P} 2$ with a 'lying down' configuration could remain hydrogen-bonded to the first- and second-hydration shells of the protrusions during the early stage of production runs, but both of them detached from the substrate gradually. This is because although the positions of first-hydration waters were fixed due to strong attractions from surface $\mathrm{Ti}$ atoms, the number of them engaged in mediation of protein adsorption was extremely small. The mobility of second-hydration waters will result in weak hydrogen-bonded connections with the protein even if an abundance of second-hydration waters are involved, not to mention only a small handful of mediating waters available here. That is, when the protein is in a doubly unfavorable situation, e.g., bridged to the rutile surface indirectly by a minority of water molecules and under insufficient position constraints from the nanostructures, it is hard to be remained in the proximity of substrate.

Unlike the above case, when direct interactions can be formed between the protein and the substrates, the results will turn out to be completely different. Take FN-III $10^{-} \mathrm{C} 1$ on the rutile surface with a cavity, for instance. The coordination of $\mathrm{Ti}_{1}$ on the left inwall did not approach saturation even with one adsorbed water molecule; thus the $\mathrm{O}_{\mathrm{CO}}$ atom was able to bind with $\mathrm{Ti}_{1}$ before other waters could penetrate into the interspace between them. Consequently, the $\mathrm{Ti}_{1}-\mathrm{O}_{\mathrm{CO}}$ bond acted as an anchoring site, around which the entire protein flipped over towards the valley of cavity to actively interact with the interfacial hydrations. The same goes for $\mathrm{FN}_{-} \mathrm{III}_{10}-\mathrm{P} 3$ on the protrusion and $\mathrm{FN}-\mathrm{III}_{10}-\mathrm{C} 2$ in the cavity in a different form. The two proteins broke through the water barriers, forming hydrogen bonds with $\mathrm{O}_{\mathrm{BO}}$ on the summit edge and $\mathrm{O}_{\mathrm{si}}$ on the inwall, respectively. The long-term nature of protein adsorption could not be unequivocally determined from the short, sub-20ns simulations reported here; nevertheless the hydrogen-bonded connections remained stable over the time scale of present simulations. Therefore, it can be inferred that direct interplays between $\mathrm{FN}-\mathrm{III}_{10}$ and rutile are capable of 'trapping' the protein on 
the substrate, or even promoting it to penetrate deep into the interior of nanostructures, no matter how many constraint facets will be provided to limit the mobility of adsorbed protein. In addition, another favorable condition for protein adsorption is that an intensive hydrogen-bond network could be developed to effectively link the $\mathrm{FN}-\mathrm{III}_{10}$ and the interfacial hydrations, while a suitable number of constraint facets are offered in appropriate orientations- $-\mathrm{FN}-\mathrm{III}_{10}-\mathrm{G} 2$ in the groove for example. The protein rotated and moved inside the groove, inevitably approaching one side of the inwall when leaving the other, as a result of position restraints from both sides. Ultimately, $\mathrm{FN}-\mathrm{III}_{10}-\mathrm{G} 2$ was confined to the interior of groove, remaining bridged to the substrate surface by the first- and second-hydration mediating waters.

As well known, the FN-III fragments do not contain any disulfide bonds, which allows them to partially unfold under applied force. To visualize the extent of unfolding of FN-III 10 molecule when in contact with a substrate, the adsorbed structures of $\mathrm{FN}-\mathrm{III}_{10}$ on different surfaces are imposed on its crystal structure by the VMD software ${ }^{44}$ (Figure 10). The residues involved in direct interactions or indirect interactions (via first-/second-hydration waters on the rutile surface) with the substrate are highlighted by yellow. It can be noticed that most parts of the two molecules in each subgraph are well-aligned, whereas some dangling ends and loops seem a little floppy. That is, the features of the native structure of $\mathrm{FN}-\mathrm{III}_{10}$ are preserved to a large extent. The residues, which contribute to protein adsorption (highlighted by yellow), in the adsorbed structure and in the crystal structure almost overlap each other, leaving only the terminal Ile96 residue (Figure 10d) deviate from its native position. Therefore, the adsorption of FN-III 10 on the rutile surface with nanostructured topography will not obviously affect protein folding, keeping the native state of the tertiary structure of $\mathrm{FN}^{-\mathrm{III}_{10}}$ nearly undisrupted.

\section{Conclusions}

MD simulations were employed in the present study to gain a detailed understanding of the interaction between a fibronectin segment $\left(\mathrm{FN}-\mathrm{III}_{10}\right)$ and the artificially nanostructured rutile surfaces. Protrusions, cavities and grooves were introduced to the surface models to emulate the nanoscale environment of anchoring substrates. The binding modes of $\mathrm{FN}-\mathrm{III}_{10}-$ rutile assembly were of paramount importance in affecting the stability of protein adsorption. Once the protein formed direct connections with the surface titaniums or broke through the water barriers to form 
hydrogen-bonds with the surface oxygens, it would tend to stay in close proximity to the substrate, or even penetrate deep into the interior of nanostructures. Moreover, the detailed shape of the nanostructures, which determines how many constraints could be imposed on the adsorbates by facets, was also demonstrated to strongly influence the residence time of adsorbed proteins within the nanostructured regions. In the case that the $\mathrm{FN}-\mathrm{III}_{10}$ could only be bridged to the substrate indirectly via interfacial hydrations, the situation may also be favorable for protein adsorption on the premise that abundant water molecules are involved in mediation and sufficient constraining facets are available to limit the mobility of adsorbed protein. On the contrary, sparse hydrogen-bonded connections between proteins and interfacial hydrations, combined with inadequate constraints from the nanostructures, would lead to a relatively large region for protein migration, facilitating the desorption of $\mathrm{FN}-\mathrm{III}_{10}$ molecules.

The findings presented in this work provide important insight into the correlation between protein adsorption and nanostructured topography of surface on a molecular level. Although it is still impossible to predict which type of nanoscale geometrical features will be most effective in promoting/inhibiting protein adsorption, thereby eliciting a particular cellular response, the introduction of tailored nano-topographies in biomedical products seems to be a potentially promising approach to improve their performance. In addition, the synergistic effect between the chemistry, topography and mechanical properties of biomaterial surfaces should be taken into account when seeking an effective control of cellular behaviors.

\section{Acknowledgements}

This work was supported by National Natural Science Foundation of China (No. 51201050), Self-Planned Task (No. SKLRS201605C) of State Key Laboratory of Robotics and System (HIT), the Fundamental Research Funds for the Central Universities (No. AUGA5710058415), and the Program of Introducing Talents of Discipline to Universities (No. B07018). This research used resources of the National Energy Research Scientific Computing Center, which is supported by the Office of Science of the U.S. Department of Energy under Contract No. DE-AC02-05CH11231. Peter T. Cummings was supported by the U.S. Department of Energy (DOE), Office of Basic Energy Sciences, Geoscience Research Program, through Grant ERKCC72 to Oak Ridge National Laboratory, which is managed for DOE by UT Battelle, LLC 
under Contract No. DE-AC05-00OR22725. 


\section{Figures}

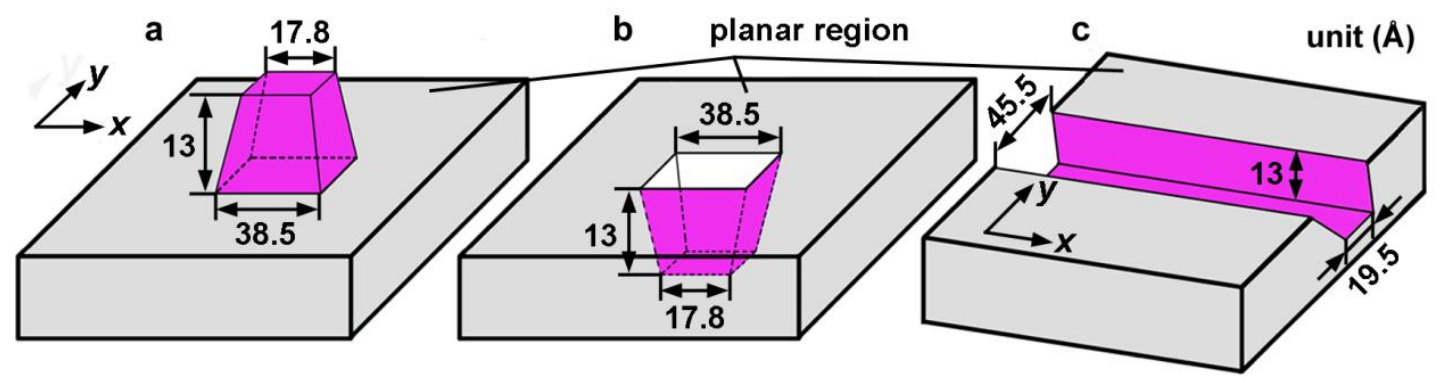

Fig. 1 Schematic illustration of substrate surfaces with a single protrusion (a), cavity (b) and groove (c).

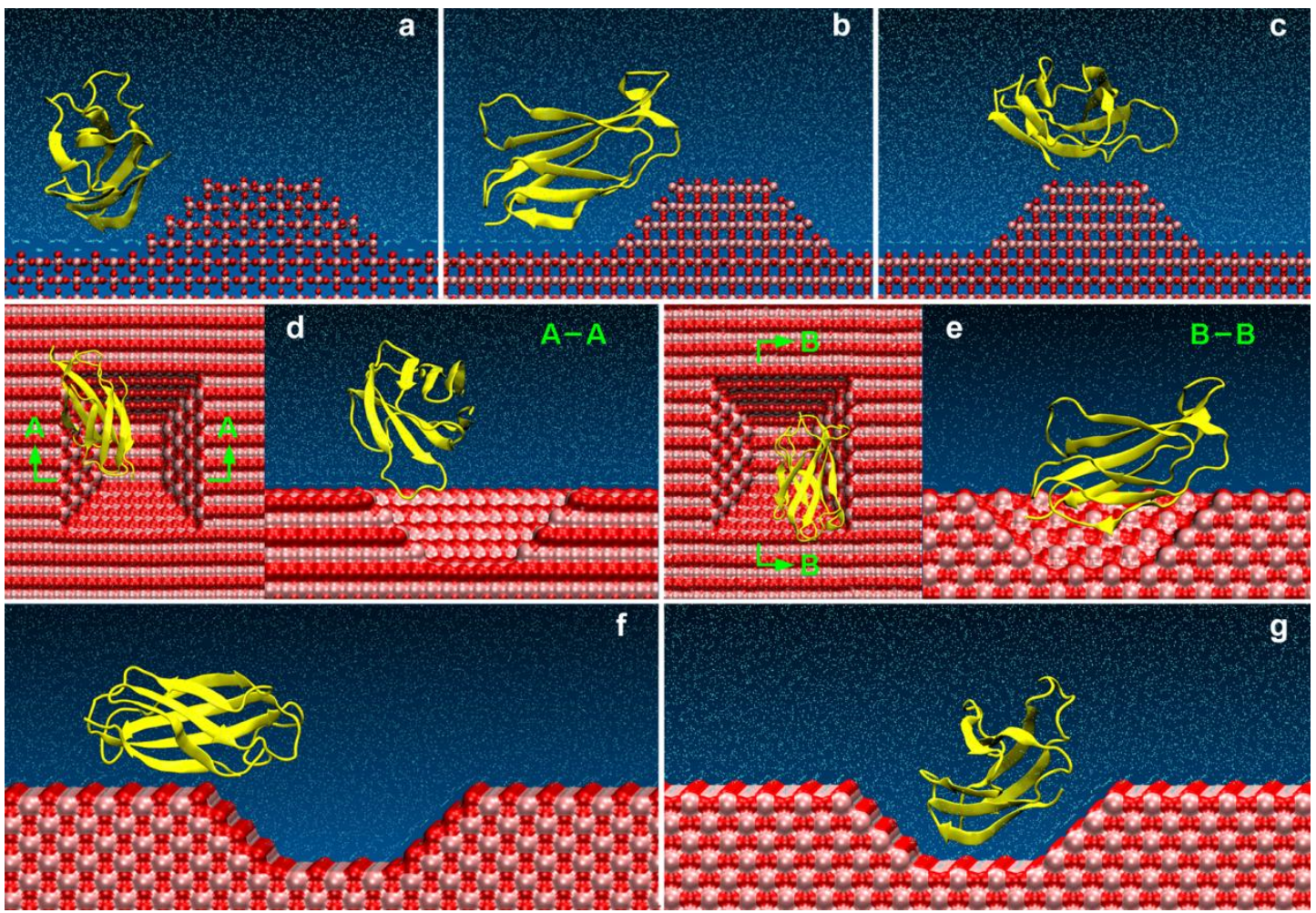

Fig. 2 Initial configurations of the $\mathrm{FN}-\mathrm{III}_{10}$-rutile assemblies. $\mathrm{FN}-\mathrm{III}_{10}$ on the surface with a protrusion (a) (c), a cavity (d) and (e), a groove (f) and (g). FN-III 10 is displayed in NewCartoon mode of $\mathrm{VMD},{ }^{44} \mathrm{TiO}_{2}$ atoms in (a) (c) are displayed in VMD's CPK mode, $\mathrm{TiO}_{2}$ atoms in (d) (g) are displayed in VMD's surface mode, oxygens of water molecules are displayed in VMD's point mode. Left snapshots in (d) and (e) are top views, right snapshots in (d) and (e) are sectional views. 

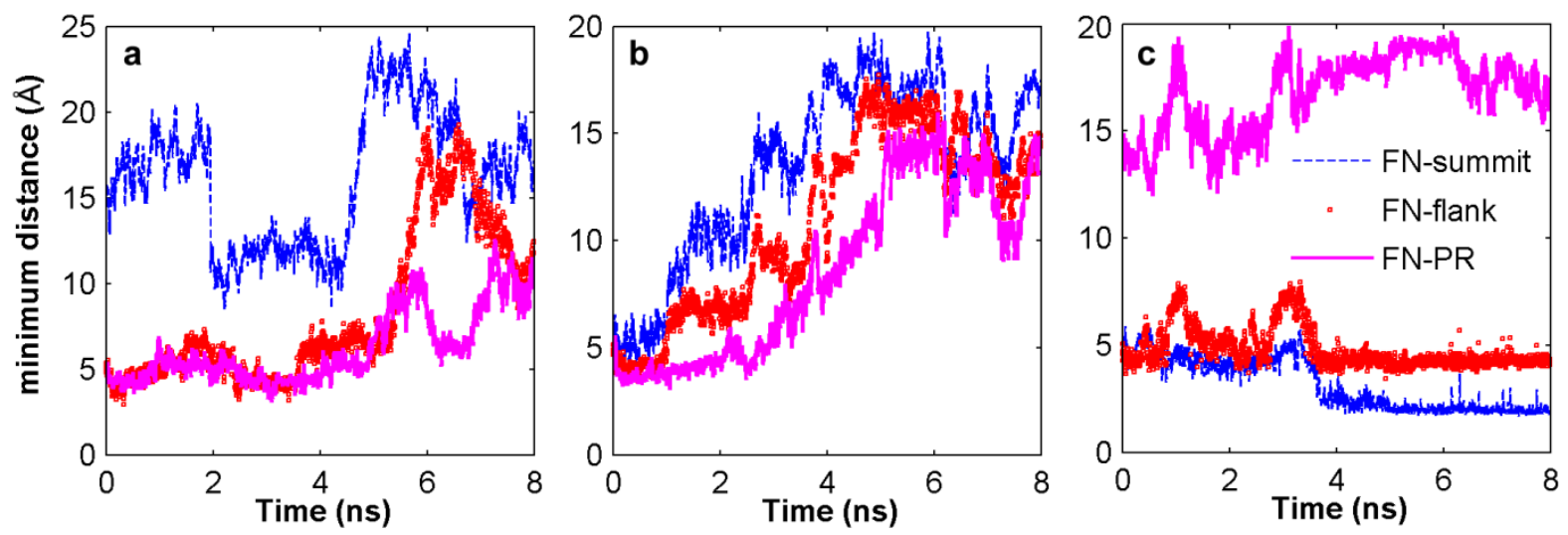

Fig. 3 Evolution of minimum distances from FN-III $10-\mathrm{P} 1$ (a), FN-III $10-\mathrm{P} 2$ (b), and FN-III $10-\mathrm{P} 3$

(c) to different parts of rutile surfaces with a single protrusion. PR stands for planar region.

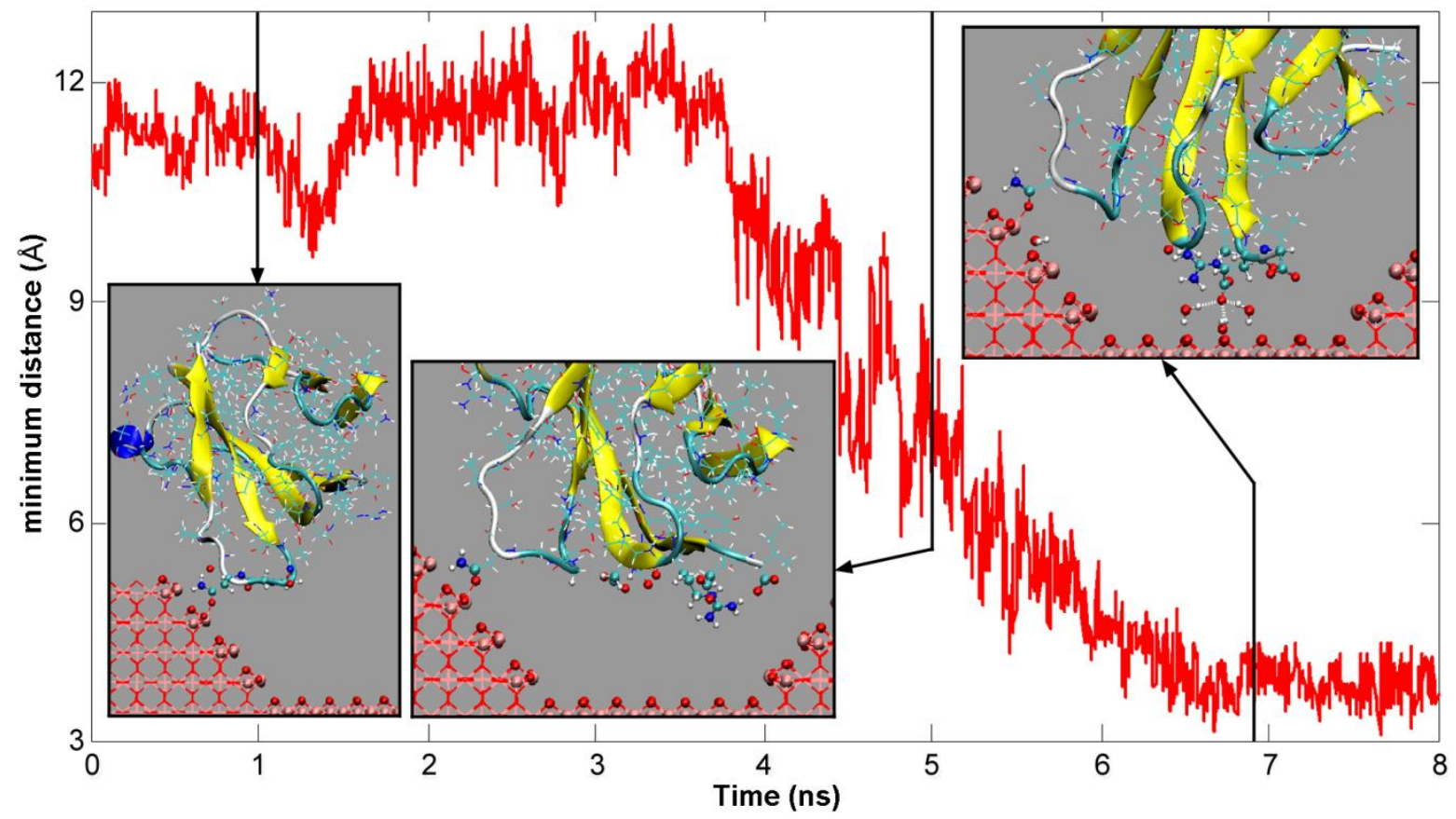

Fig. 4 Evolution of minimum distance from $\mathrm{FN}-\mathrm{III}_{10}-\mathrm{C} 1$ to the valley of cavity and protein conformations at different time points. To clearly display the interior of cavity, parts of inwalls are hidden in the snapshots. 


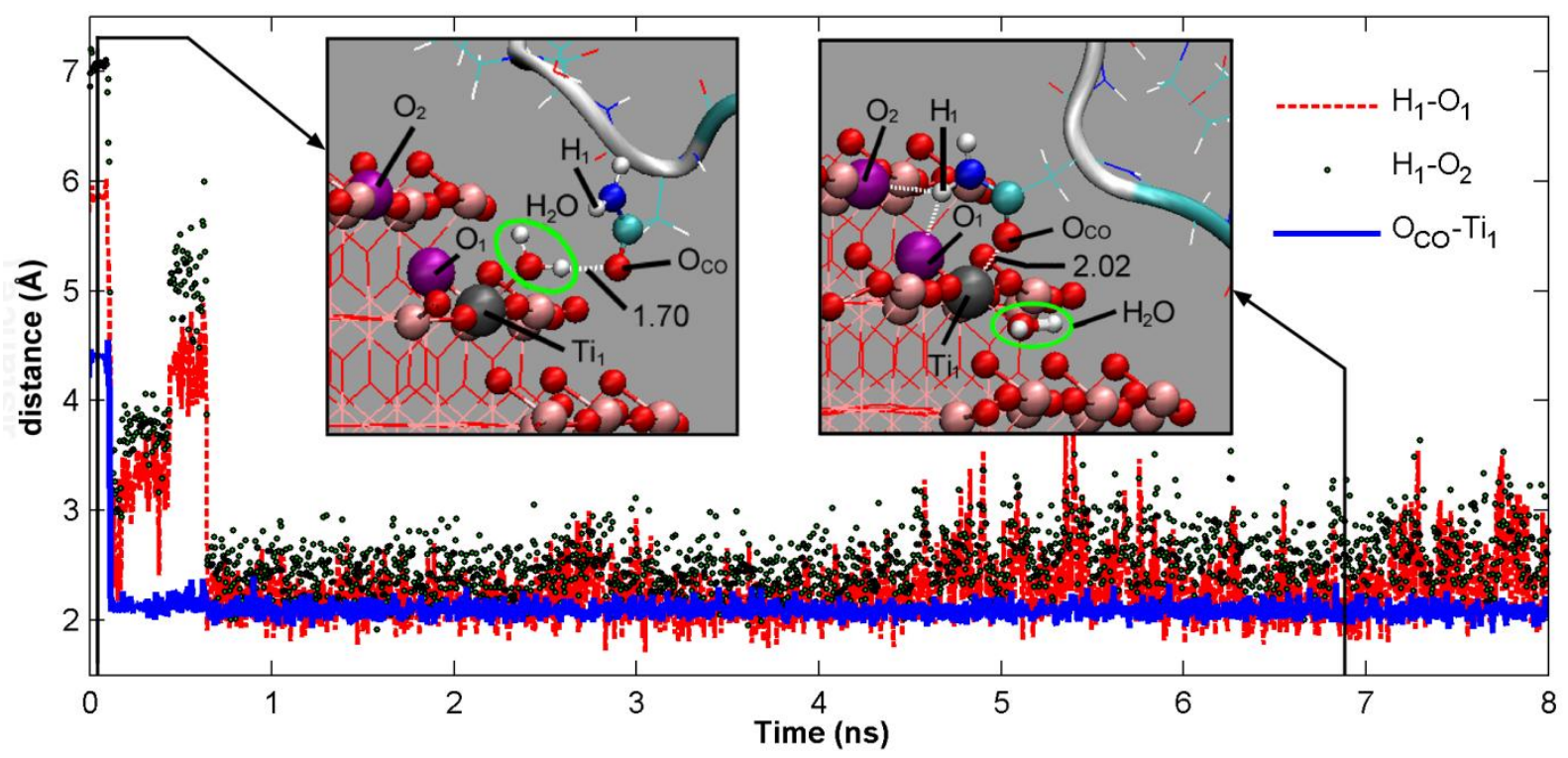

Fig. 5 Evolution of distances from carbonyl and amide groups in the side chain of residue Asn42 (FN-III $10-\mathrm{C} 1)$ to the specific top-layer $\mathrm{TiO}_{2}$ atoms on the inwall of cavity. To clearly display the interior of cavity, parts of inwalls are hidden in the snapshots.
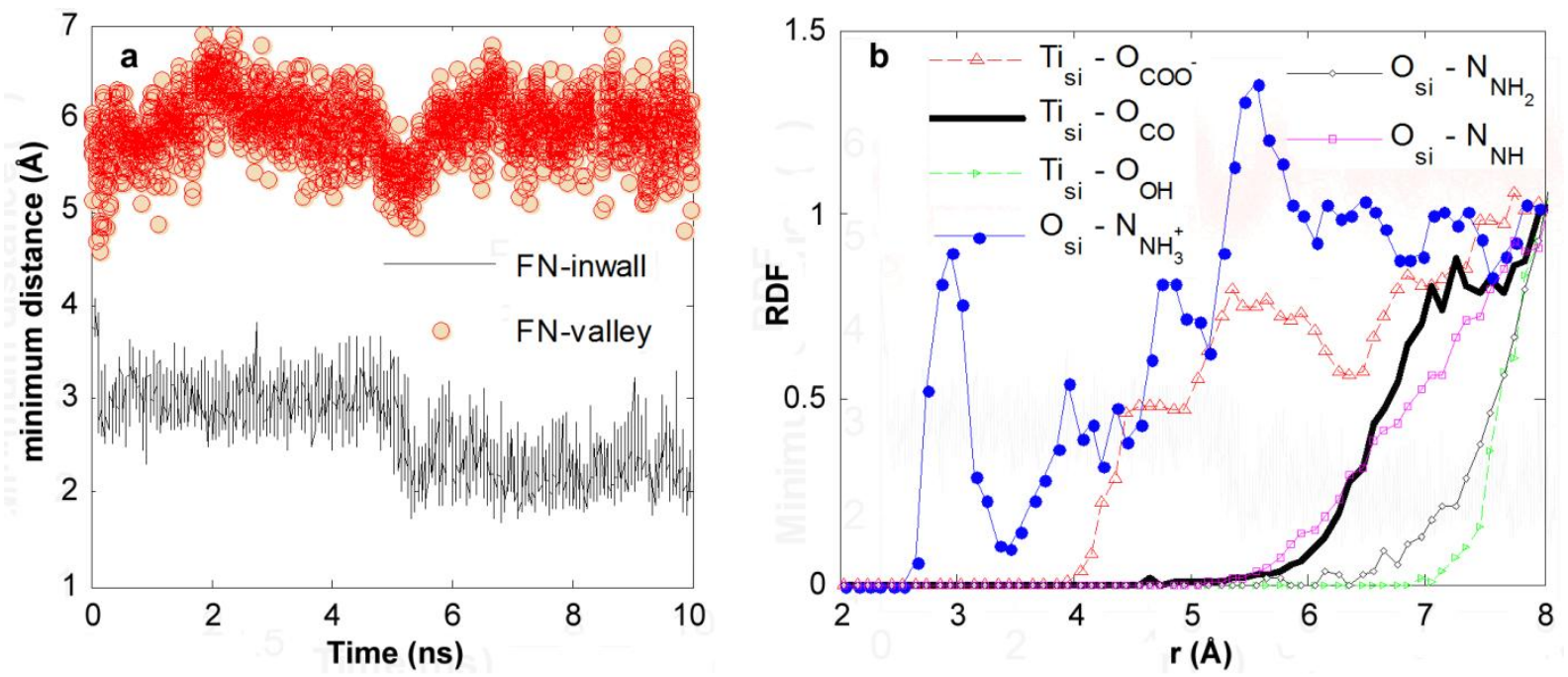

Fig. 6 Evolution of minimum distances from $\mathrm{FN}-\mathrm{III}_{10}-\mathrm{C} 2$ to the inwall, valley of cavity (a) and the RDFs between specific protein atoms and $\mathrm{TiO}_{2}$ atoms (b). $\mathrm{Ti}_{\mathrm{si}}$ and $\mathrm{O}_{\mathrm{si}}$ refer to the top-layer $\mathrm{Ti}$ and $\mathrm{O}$ on the inwall, respectively. 


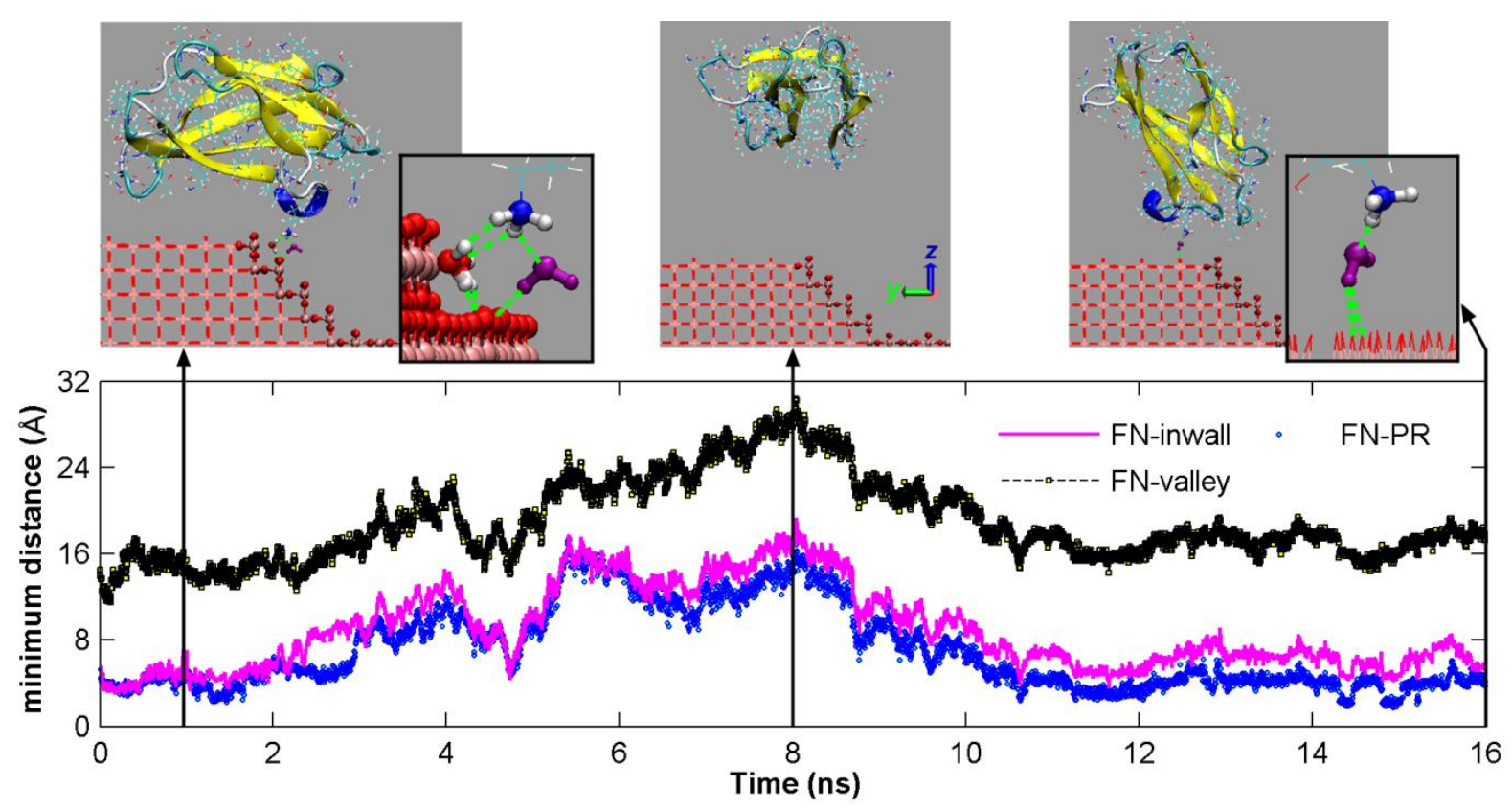

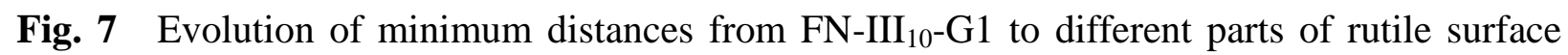
with a single groove. PR stands for planar region.
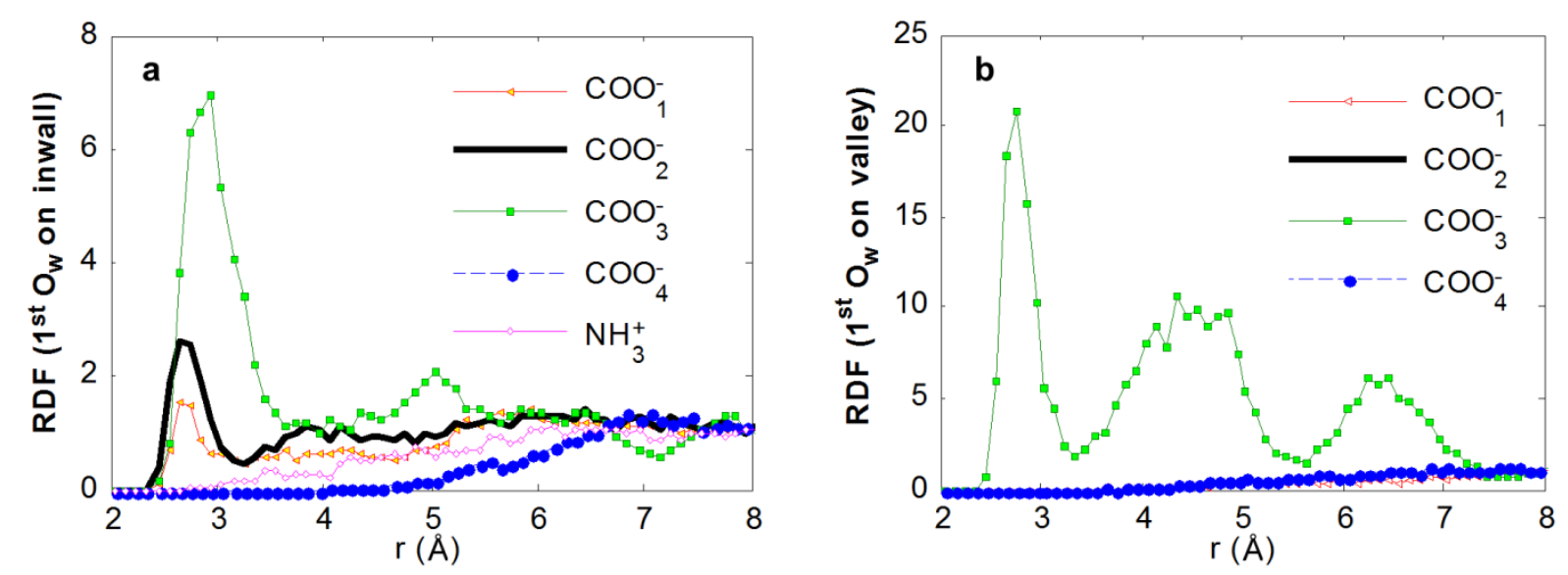

Fig. 8 RDFs between functional groups of $\mathrm{FN}-\mathrm{III}_{10}-\mathrm{G} 2$ and the first-hydration water $\mathrm{O}_{\mathrm{w}}$ on inwall (a) and valley (b) of groove. $\mathrm{COO}^{-} \sim \mathrm{COO}_{4}^{-}$refer to the carboxyl groups of residue Glu9, Asp23, Glu95 and Ile96 in sequence. 

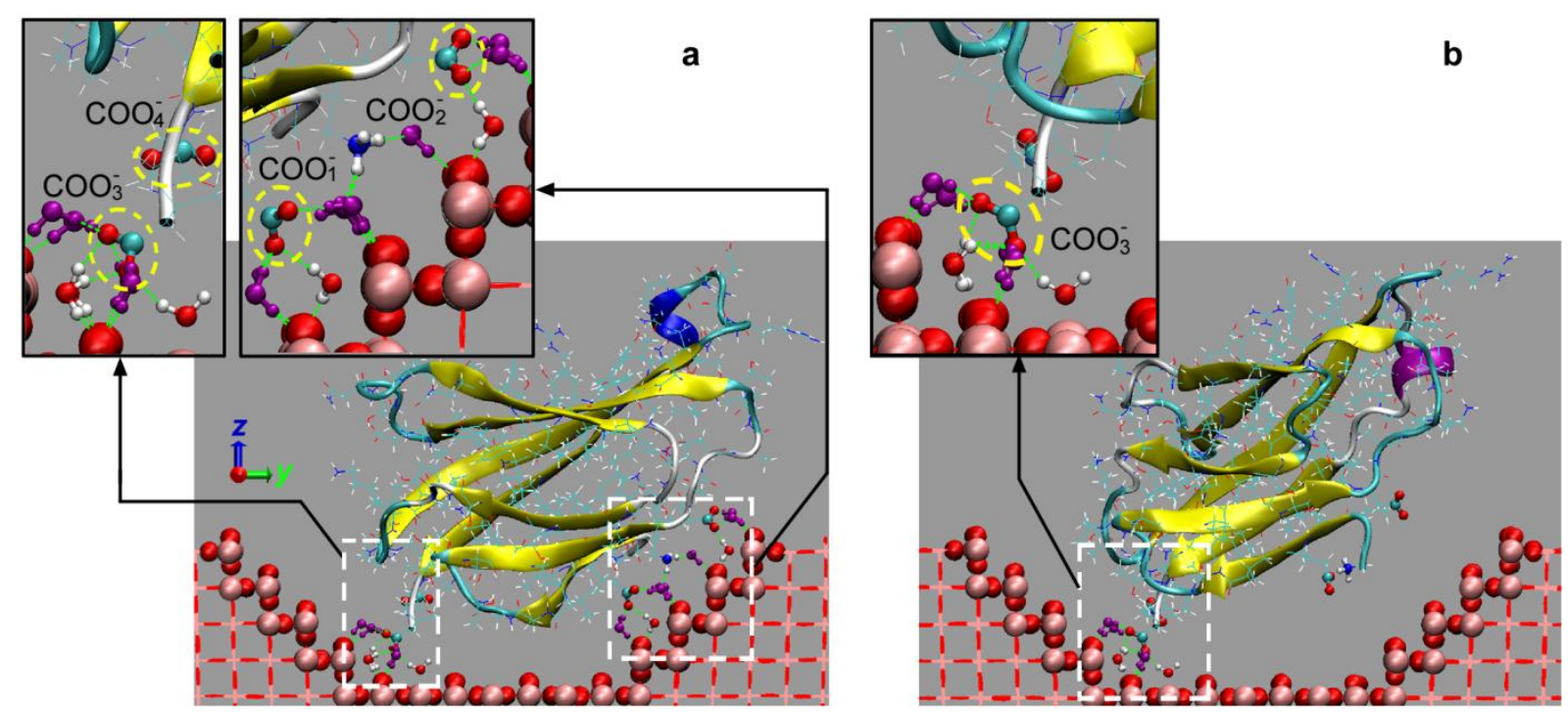

Fig. 9 Conformations of $\mathrm{FN}-\mathrm{III}_{10}-\mathrm{G} 2$ on the grooved surface at $t=13.0 \mathrm{~ns}$ (a) and $15.0 \mathrm{~ns}$ (b). FN-III 10 is displayed in combined mode of $\mathrm{VMD}^{44}$ (NewCartoon and line mode), functional groups in close proximity to substrate and the first-/second-hydration waters directly interacting with $\mathrm{FN}-\mathrm{III}_{10}$ are displayed in VMD's CPK mode, the $\mathrm{TiO}_{2}$ atoms locating at the edge of groove and the residual ones are displayed in VMD's VDW and line mode, respectively. $\beta$-strand, $\alpha$-helix, $3_{10}$-helix and second-hydration mediating waters are highlighted by yellow, violet red, dark blue, and purple, respectively. The residual waters are omitted for clarity.
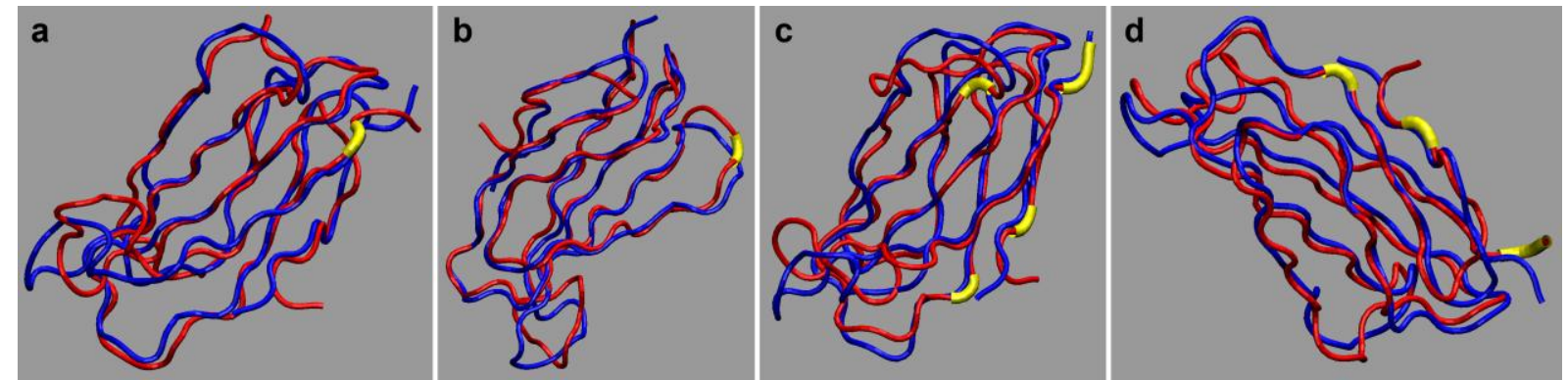

Fig. 10 Adsorbed structure of $\mathrm{FN}-\mathrm{III}_{10}$ (red) superimposed on the crystal structure of $\mathrm{FN}-\mathrm{III}_{10}$ (blue): (a) FN-III $10^{-} \mathrm{P} 3$, (b) $\mathrm{FN}-\mathrm{III}_{10}-\mathrm{C} 1$, (c) $\mathrm{FN}-\mathrm{III}_{10}-\mathrm{C} 2$, (d) $\mathrm{FN}-\mathrm{III}_{10}-\mathrm{G} 2$. FN-III 10 is displayed in Tube mode of $\mathrm{VMD},{ }^{44}$ the residues involved in direct/indirect (via first-/second-hydration waters on the rutile surface) interactions with the substrate are highlighted by yellow. 


\section{References}

[1] M. Ozboyaci, D. B. Kokh, S. Corni, R. C. Wade, Modeling and simulation of protein-surface interactions: Achievements and challenges, Q. Rev. Biophys. 49 (2016) Article ID: e4.

[2] X. Wang, G. Herting, I. O. Wallinder, E. Blomberg, Adsorption of lysozyme on silver and its influence on silver release, Langmuir 30 (2014) 13877-13889.

[3] A. Vogler, Protein adsorption in three dimensions, Biomaterials 33 (2012) 1201-1237.

[4] B. Kasemo, Biological surface science, Surf. Sci. 500 (2002) 656-677.

[5] M. S. Lord, M. Foss, F. Besenbacher, Influence of nanoscale surface topography on protein adsorption and cellular response, Nano Today 5 (2010) 66-78.

[6] A. C. De Luca, M. Zink, A. Weidt, S. G. Mayr, A. E. Markaki, Effect of microgrooved surface topography on osteoblast maturation and protein adsorption, J. Biomed. Mater. Res. Part A 103 (2015) 2689-2700.

[7] Q. L. Huang, X. J. Liu, T. A. Elkhooly, R. R. Zhang, X. Yang, Z. J. Shen, Q. L. Feng, Preparation and characterization of $\mathrm{TiO}_{2} /$ silicate hierarchical coating on titanium surface for biomedical applications, Mater. Sci. Eng. C-Mater. Biol. Appl. 60 (2016) 308-316.

[8] N. Giamblanco, E. Martines, G. Marletta, Laminin adsorption on nanostructures: Switching the molecular orientation by local curvature changes, Langmuir 29 (2013) $8335-8342$.

[9] P. Elter, R. Lange, U. Beck, Atomic force microscopy studies of the influence of convex and concave nanostructures on the adsorption of fibronectin, Colloid Surf. B-Biointerfaces 89 (2012) 139-146.

[10] H. Chen, W. Song, F. Zhou, Z. Wu, H. Huang, J. H. Zhang, Q. Lin, B. Yang, The effect of surface microtopography of poly(dimethylsiloxane) on protein adsorption, platelet and cell adhesion, Colloid Surf. B-Biointerfaces 71 (2009) 275-281.

[11] S. Monti, RAD16II $\beta$-sheet filaments onto titanium dioxide: Dynamics and adsorption properties, J. Phys. Chem. C 111 (2007) 16962-16973.

[12] A. A. Skelton, T. Liang, T. R. Walsh, Interplay of sequence, conformation and binding at the titania-peptide interface as mediated by water, ACS Appl. Mater. Interfaces 1 (2009) 
$1482-1491$.

[13] W. Yang, X. Xi, X. Shen, P. Liu, Titania nanotubes dimensions-dependent protein adsorption and its effect on the growth of osteoblasts, J. Biomed. Mater. Res. Part A 102A (2014) 3598-3608.

[14] G. Raffaini, F. Ganazzoli, Surface topography effects in protein adsorption on nanostructured carbon allotropes, Langmuir 29 (2013) 4883-4893.

[15] C. Y. Wu, M. J. Chen, A. A. Skelton, P. T. Cummings, T. Zheng, Adsorption of arginine-glycine-aspartate tripeptide onto negatively charged rutile (110) mediated by cations: The effect of surface hydroxylation, ACS Appl. Mater. Interfaces 5 (2013) $2567-2579$.

[16] C. Y. Wu, A. A. Skelton, M. J. Chen, L. Vlček, P. T. Cummings, Modeling the interaction between integrin-binding peptide (RGD) and rutile surface: The effect of cation mediation on Asp adsorption, Langmuir 28 (2012) 2799-2811.

[17] C. Y. Wu, A. A. Skelton, M. J. Chen, L. Vlček, P. T. Cummings, Modeling the interaction between integrin-binding peptide (RGD) and rutile surface: The effect of $\mathrm{Na}^{+}$on peptide adsorption, J. Phys. Chem. C 115 (2011) 22375-22386.

[18] J. A. Libera, H. Cheng, M. Olvera de la Cruz, M. J. Bedzyk, Direct observation of cations and polynucleotides explains polyion adsorption to like-charged surfaces, J. Phys. Chem. B 109 (2005) 23001-23007.

[19] H. Cheng, K. Zhang, J. A. Libera, M. Olvera de la Cruz, M. J. Bedzyk, Polynucleotide adsorption to negatively charged surfaces in divalent salt solutions, Biophys. J. 90 (2006) $1164-1174$.

[20] M. D. Pierschbacher, E. Ruoslahti, Cell attachment activity of fibronectin can be duplicated by small synthetic fragments of the molecule, Nature 309 (1984) 30-33.

[21] L. M. Alison, S. H. Timothy, The three-dimensional structure of the tenth type III module of fibronectin: An insight into RGD-mediated interactions, Cell 71 (1992) 671-678.

[22] W. H. Baur, A. A. Khan, Rutile-type compounds. VI. $\mathrm{SiO}_{2}, \mathrm{GeO}_{2}$ and a comparison with other rutile-type structures, Acta Cryst. B27 (1971) 2133-2139.

[23] M. B. Hugenschmidt, L. Gamble, C. T. Campbell, The interaction of $\mathrm{H}_{2} \mathrm{O}$ with a $\mathrm{TiO}_{2}$ (110) surface, Surf. Sci. 302 (1994) 329-340. 
[24] S. Benkoula, O. Sublemontier, M. Patanen, C. Nicolas, F. Sirotti, A. Naitabdi, F. Gaie-Levrel, E. Antonsson, D. Aureau, F. Ouf, S. Wada, A. Etcheberry, K. Ueda, C. Miron, Water adsorption on $\mathrm{TiO}_{2}$ surfaces probed by soft X-ray spectroscopies: Bulk materials vs. isolated nanoparticles. Sci. Rep. 5 (2015) Article ID: 15088.

[25] D. Brinkley, M. Dietrich, T. Engel, P. Farrall, G. Gantner, A. Schafer, A. Szuchmacher, A modulated molecular beam study of the extent of $\mathrm{H}_{2} \mathrm{O}$ dissociation on $\mathrm{TiO}_{2}(110)$, Surf. Sci. 395 (1998) 292-306.

[26] D. A. Duncan, F. Allegretti, D. P. Woodruff, Water does partially dissociate on the perfect $\mathrm{TiO}_{2}(110)$ surface: A quantitative structure determination, Phys. Rev. B 86 (2012) Article ID: 045411.

[27] L. E. Walle, A. Borg, P. Uvdal, A. Sandell, Experimental evidence for mixed dissociative and molecular adsorption of water on a rutile $\mathrm{TiO}_{2}$ (110) surface without oxygen vacancies. Phys. Rev. B 80 (2009) Article ID: 235436.

[28] P. J. D. Lindan, C. Zhang, Exothermic water dissociation on the rutile $\mathrm{TiO}_{2}(110)$ surface, Phys. Rev. B 72 (2005) Article ID: 075439.

[29] C. E. Patrick, F. Giustino, Structure of a water monolayer on the anatase $\mathrm{TiO}_{2}(101)$ surface, Phys. Rev. Appl. 2 (2014) Article ID: 014001.

[30] W. Zhang, J. Yang, Y. Luo, S. Monti, V. Carravetta, Quantum molecular dynamics study of water on $\mathrm{TiO}_{2}(110)$ surface, J. Chem. Phys. 129 (2008) Article ID: 064703.

[31] T. Zheng, C. Y. Wu, M. J. Chen, P. T. Cummings, A DFT study of water adsorption on rutile (110) surface: Effects of surface steps. Submitted to Langmuir.

[32] M. Matsui, M. Akaogi, Molecular dynamics simulation of the structural and physical properties of the four polymorphs of $\mathrm{TiO}_{2}$, Mol. Simul. 6 (1991) 239-244.

[33] C. D. Dickinson, B. Veerapandian, X. P. Dai, R. C. Hamlin, N. Xuong, E. Ruoslahtil, K. R. Ely, Crystal structure of the tenth type III cell adhesion module of human fibronectin. J. Mol. Biol. 236 (1994) 1079-1092.

[34] W. D. Cornell, P. Cieplak, C. I. Bayly, I. R. Gould, K. M. Merz, D. M. Ferguson, D. C. Spellmeyer, T. Fox, J. W. Caldwell, P. A. Kollman, A second generation force field for the simulation of proteins, nucleic acids, and organic molecules, J. Am. Chem. Soc. 117 (1995) 5179-5197. 
[35] H. J. C. Berendsen, J. R. Grigera, T. P. Straatsma, The missing term in effective pair potentials, J. Phys. Chem. 91 (1987) 6269-6271.

[36] V. Carravetta, S. Monti, Peptide- $\mathrm{TiO}_{2}$ surface interaction in solution by ab initio and molecular dynamics simulations, J. Phys. Chem. B 110 (2006) 6160-6169.

[37] M. P. Allen, D. J. Tildesley, In Computer simulation of liquids, 1st ed., Oxford University Press Inc.: New York, 1989, pp. 22-24.

[38] W. G. Hoover, Canonical dynamics: Equilibrium phase--space distributions, Phys. Rev. A 31 (1985) 1695-1697.

[39] R. W. Hockney, J. W. Eastwood, In Computer Simulation Using Particles, 1st ed., Taylor \& Francis Group: New York, 1988, pp. 22-30.

[40] M. S. Niepel, B. Fuhrmann, H. S. Leipner, T. Groth, Nanoscaled surface patterns influence adhesion and growth of human dermal fibroblasts, Langmuir 29 (2013) 1327813290.

[41] P. Roach, D. Farrar, C. C. Perry, Surface tailoring for controlled protein adsorption: Effect of topography at the nanometer scale and chemistry, J. Am. Chem. Soc. 128 (2006) 3939-3945.

[42] T. Zheng, C. Y. Wu, M. J. Chen, Early adsorption of collagen on the reduced rutile (110) surface mediated by water: A molecular dynamics study, Surf. Sci. 616 (2013) 51-59.

[43] D. P. Song, M. J. Chen, Y. C. Liang, Q. S. Bai, J. X. Chen, X. F. Zheng, Adsorption of tripeptide RGD on rutile $\mathrm{TiO}_{2}$ nanotopography surface in aqueous solution, Acta. Biomater. 6 (2010) 684-694.

[44] W. Humphrey, A. Dalke, K. Schulten, VMD: Visual molecular dynamics, J. Mol. Graph. Model. 14 (1996) 33-38.

[45] K. Wilson, S. J. Stuart, A. Garcia, R. A. Latour, A molecular modeling study of the effect of surface chemistry on the adsorption of a fibronectin fragment spanning the 7-10th type III repeats, J. Biomed. Mater. Res. 69A (2004) 686-698.

[46] A. Krammer, D. Craig, W. E. Thomas, K. Schulten, V. Vogel, A structural model for the force regulated integrin binding to fibronectin's RGD-synergy site, Matrix Biol. 21 (2002) 139-147.

[47] P. Elter, R. Lange, U. Beck, Electrostatic and dispersion interactions during protein 
adsorption on topographic nanostructures, Langmuir 27 (2011) 8767-8775.

\section{Graphical Abstract}

[48]

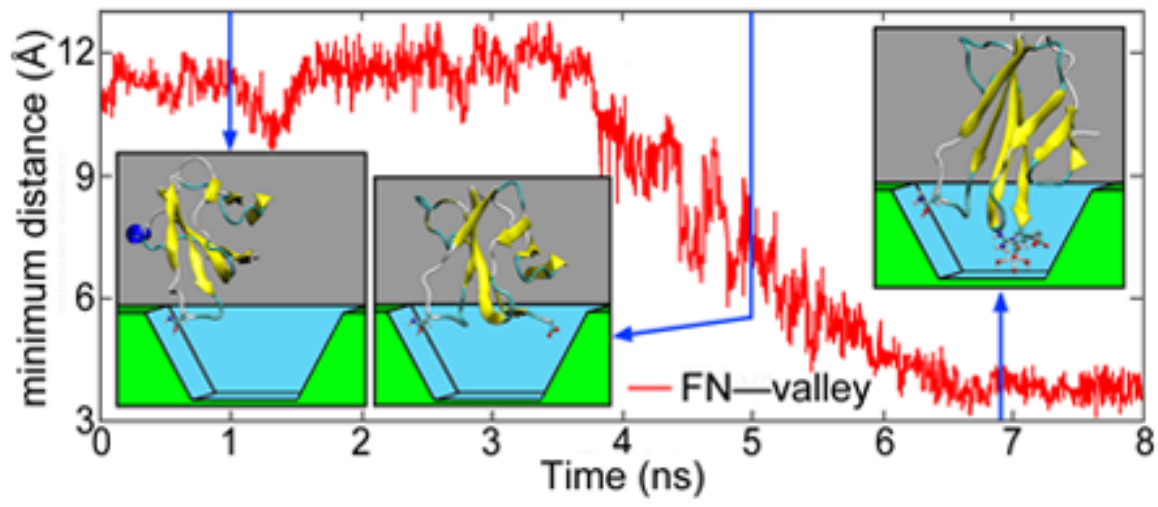

[49] 